RESEARCH PAPER

\title{
THE IMPACT OF SHEAR GAP SIZE ON THE QUALITY OF THE SHEARED SURFACE IN ELECTRICAL STEEL SHEET BLANKING
}

\author{
Emil Spišák ${ }^{l}$, Janka Majerníkovál , Luboš Kaščák ${ }^{l}$, Peter Mulidrán ${ }^{1}$ \\ ${ }^{1)}$ Technical University of Košice, Faculty of Mechanical Engineering, Košice, Slovakia
}

*Corresponding author: emil.spisak@tuke.sk, Tel.: +421 55602 3502, Department of Mechanical Engineering Technologies and Materials, Technical University of Košice, Letná 9, 04200 Košice, Slovakia)

Received: 30.04 .2020

Accepted: 28.05.2020

\begin{abstract}
The quality of the sheared surface when blanking, also known as die-cutting, is the result of several factors. Based on current knowledge about blanking, the following technological parameters - shear gap size, blunting of the shearing tool, lubrication in the shearing process, and deformation rate - can be considered as decisive parameters on the quality of the sheared surface. The main material characteristics include yield strength, tensile strength, ductility, and ferrite grain size. The paper is focused on the influence of the shear gap on the quality of the shear surface of electrical sheets with different chemical composition and different mechanical properties. The quality of the cutting surface was characterized by the size of the plastic cutting area. The relationships between the size of the shear gap, which ranged from 1 to $7 \%$ of the thickness of the cut material and the size of the plastic shear area, were evaluated and measured macroscopically.
\end{abstract}

Keywords: electrical steel; shear gap; sheared surface

\section{INTRODUCTION}

The constant pressure to reduce energy consumption brings along the need to increase energy efficiency and reduce the energy intensity of industrial machinery and equipment. Increasing energy efficiency is mostly focused on improving the technical parameters of energy equipment. One way of reducing energy intensity is to increase the efficiency of electric drives for machines and equipment. This is possible by using materials that have lower energy losses. Energy losses in electrical machines are greatly affected by the type of electrical steel used.

Electrical steel is one of the basic materials, used in the production of electrical rotating machines and transformers. Two major characteristics of electrical machines - performance and efficiency - depend on the quality of electrical steels. The quality of steel directly affects the efficiency of the use of electricity. The efficient use of electricity is one of the main factors determining the range of electric vehicles. Therefore, in recent years considerable attention has been paid to the issue of further improving the quality of isotropic steel sheets for electrical engineering and optimizing their production and processing. The resulting magnetic properties of electrical steel depend on numerous factors, including the chemical composition of the material, metallurgical purity, structural and metallographic characteristics, equilibrium or non-equilibrium changes, precipitate morphology and distribution, segregation enrichment of grain boundary surfaces, processing and heat treatment, deformation, and residual stress.

At present, electrical steel sheets are produced in metallurgical plants and delivered to the customers in the semi-processed and fully processed state. In Europe, the use of electrical steel for the production of electric motor cores in the semi-processed state is preferred. Asia and America typically use electrical steel in a fully processed state. This difference is caused by using different electrical steel processing technologies and varying technological know-how across countries. The increase in the use of electrical steel in the fully-processed state is caused by the possibility of its direct use without final processing, in less demanding applications, and in the availability of higher quality grades, that are not available in the semi-processed state.

Electrical steels are one of the most important magnetic materials produced today. Despite the increasing use of permanent magnets, their use for the production of stator and transformer cores is dominant. There are two basic types of electrical steels: grain-oriented steel and non-grain-oriented steel, both fully and semi-processed. The non-grain-oriented electrical steels are produced in the form of cold-rolled sheets with a thickness of $0.25,0.35,0.5$ and $0.65 \mathrm{~mm}$ and are classified according to the maximum specific losses in $\mathrm{W} / \mathrm{kg}$.
Isotropic electrical steels belong to the group of soft magnetic materials and are used in various electrical applications and equipment. They are characterized by low losses caused by magnetization alternating electric field. High-silicon steels (often referred to as silicon steels) were developed at the beginning of the 20th century and very quickly became the preferred material used to build the cores of large transformers, motors, and generators. In 2018, the share of electrical steel increased to $3 \%$ of the total steel production [1], [2]. With the growth of electric vehicle production, the consumption of steel for the production of electric motor cores is also expected to increase.

The requirements for these steels are high permeability and induction, low magnetic losses and low magnetostriction. In certain specific cases, exceptional mechanical properties are also required. High permeability and induction reduce the size and weight of the cores. Low magnetic losses reduce heat generation and energy consumption. Mechanical properties affect shearability, resistance to fatigue fracture resulting from sudden changes in mechanical stress and resistance to material deformation at high rotor or stator speeds [3-5].

The chemical composition of these steels is similar - especially as far as the basic alloying elements are concerned, and the manufacturing processes have not changed significantly for years. However, steel losses with a given $\mathrm{Si}$ and $\mathrm{Al}$ contents are much lower today than in previous decades. According to the electrical steel manufacturers, they made very little change in the basic chemistry used in standard, commercial types. International, national (EN- STN 10126) and (EN- STN 10165), EN-STN 10126 and company standards H-204 (Internal standard Embraco TST00H-204) determine only maximum specific losses (and often minimum polarization/throughput), but in principle they do not reduce the loss limit.

Conventional electromagnetic properties of electrical steels are defined by wattage losses, magnetic induction, and magnetic polarization. The mentioned properties are determined by microstructural and substructural parameters such as grain size and morphology, the density of crystallographic disorders, preferred crystallographic orientation, the chemical composition of the solid solution and the presence of secondary particles. Individual parameters used in the thermomechanical process of production of electrical steel directly influence the final magnetic quality of materials.

Most electrical equipment manufacturers, with the exception of the transformer and specialty applications manufacturers, require low core losses and high magnetic induction from the electrical steel. These magnetic properties are mainly influenced by grain size and crystallographic texture.

The effect of grain size on magnetic properties was first described in 1912 by W. E. Ruder, who discovered that hysteresis losses decrease as grain size increases. Since then, the effect of grain growth has been the subject of numerous scientific papers and literature. Hence, as the grain size increases, hysteresis losses 
decrease, while eddy current losses increase. The result is an optimum grain size that minimizes the sum of hysteresis and eddy current losses. The optimum grain size varies depending on the chemical composition and texture. J. T. Park and J. K. Kim [6] specified optimum grain size of $100-150 \mu \mathrm{m}$ for steels containing $1.85 \%$ and $3.2 \% \mathrm{Si}$. On the other hand, the texture also greatly affects hysteresis losses. The authors further claimed in their study that the material with a favorable texture exhibits lower core losses than the one with an unfavorable texture - despite having the same grain size. This indicates that losses can be further reduced by an appropriate texture. In view of the above, a key factor in the production and finishing of isotropic steels is the growth of grains to the optimum size with a favorable texture.

\section{THE EFFECT OF SHEARING ON THE DEGRADATION OF MAGNETIC PROPERTIES}

When the sheet is sheared and the lamella shape is formed, the metal is separated, and the crystal lattice is disrupted. The properties of the material near the sheared edge are significantly altered. In 1971, Carlberg [7] first suggested that the area of degradation of properties near the sheared edge of an electrical steel strip can be considered as wide as $1 \mathrm{~mm}$. Schmidt [8] identified a shear-affected area at a width of $0.35 \mathrm{~mm}$ with an increase in losses of $30-40 \%$ and a corresponding induction decrease of $70 \%$ at the same magnetic field strength. In 1992, T. Nakata [9] stated that the degradation of the magnetic properties of the strip of non-oriented silicon steel sheet due to shearing is in the region of $10 \mathrm{~mm}$ from the sheared edge and the deterioration is particularly significant $5 \mathrm{~mm}$ from the edge. Several other authors including F. Ossart, E. Hug, O. Hubert, C. Buvat, R. Billardon [10], and A. Kedous-Lebouc [11] paid attention to local degradation in the active part of the stator lamella sheared from an electrical steel sheet. Subsequently, V. Manescu et al. [12] and N. Takahashi [13], [14] compared the impact in terms of different shearing technologies.

In spite of different initial views, the average shear-affected area is generally considered to be equal to the thickness of the sheared material. The size of the affected area depends on parameters such as steel hardness, ductility, tensile strength, yield strength, surface insulation, grain size, shear clearance, and shearing tool geometry. Many authors researched microstructural changes during the recovery of distorted grains, e.g. Talbot [15] examining pure iron and $\mathrm{Hu}$ [16] silicon steel. Most of the works are devoted to restoring the magnetic properties after annealing in the area of deformation after shearing and rolling, see Landgraf [17].

Fig. 1 shows the principle of blanking process and Fig. 2 shows zones of a sheared surface.

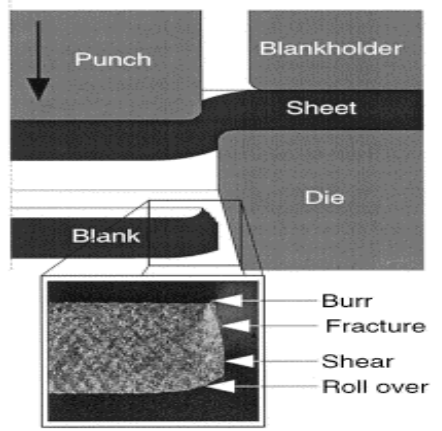

Fig. 1 Scheme of the blanking process and a sheared surface profile

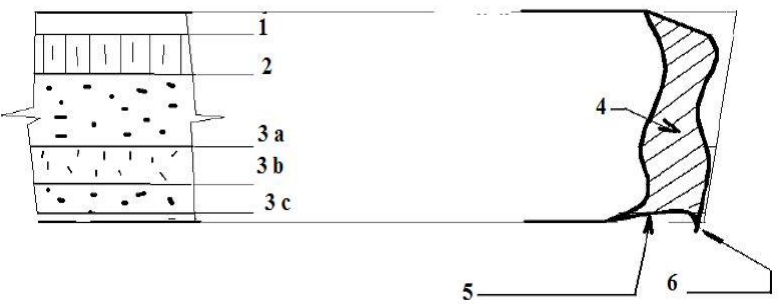

Fig. 2 Zones of a sheared surface $(1-$ rollover, 2 - plastic shear, 3a fracture, 3b - abrasion, $3 \mathrm{c}$ - fracture, 4 - hardened area, 5 - tool mark, 6 burr)

\section{MATERIAL AND METHODS}

\section{Materials used in the experimental study}

Thin electrical steel sheets with the following designations were used for experimental research: material B - steel ISOVAC M450 - 50K Voest Alpine, material C - steel M450 - 50K Arcelor Mittal and material E - steel M450 50PP Thyssen Krupp Bochum.

The chemical composition of the used steel sheets is given in Tables 1, 2 and 3 . The materials differed mainly in the different silicon contents. For sheet B ISOVAC M 450 - 50K (Voest Alpine), the Si content was $0.574 \%$, for sheet $\mathrm{C}-$ M450 - 50K (Arcelor Mittal) the Si content was $0.148 \%$ and for E - steel M450 - 50PP (Thyssen Krupp Bochum) the Si content was $1.630 \%$.

Table 1 Chemical composition of material - B [wt.\%]

\begin{tabular}{|c|c|c|c|c|c|c|}
\hline $\mathbf{C}$ & $\mathbf{M n}$ & $\mathbf{S i}$ & $\mathbf{P}$ & $\mathbf{S}$ & $\mathbf{A l}$ & $\mathbf{C u}$ \\
\hline 0.0059 & 0.506 & 0.574 & 0.034 & 0.0036 & 0.418 & 0.011 \\
\hline $\mathbf{N i}$ & $\mathbf{C r}$ & $\mathbf{A s}$ & $\mathbf{N b}$ & $\mathbf{M o}$ & $\mathbf{C o}$ & $\mathbf{S n}$ \\
\hline 0.010 & 0.019 & $<0.001$ & $<0.002$ & 0.003 & $<0.002$ & $<0.002$ \\
\hline $\mathbf{S b}$ & $\mathbf{W}$ & $\mathbf{B}$ & $\mathbf{C a}$ & $\mathbf{Z r}$ & $\mathbf{N}_{\mathbf{2}}$ & \\
\hline$<0.002$ & $<0.003$ & $<0.0002$ & $<0.0002$ & $<0.001$ & 0.0017 & \\
\hline
\end{tabular}

Table 2 Chemical composition of material - C [wt.\%]

\begin{tabular}{|c|c|c|c|c|c|c|}
\hline $\mathbf{C}$ & $\mathbf{M n}$ & $\mathbf{S i}$ & $\mathbf{P}$ & $\mathbf{S}$ & $\mathbf{A l}$ & $\mathbf{C u}$ \\
\hline 0.0026 & 0.609 & 0.148 & 0.089 & 0.0075 & 0.117 & 0.017 \\
\hline $\mathbf{N i}$ & $\mathbf{C r}$ & $\mathbf{A s}$ & $\mathbf{N b}$ & $\mathbf{M o}$ & $\mathbf{C o}$ & $\mathbf{S n}$ \\
\hline 0.021 & 0.028 & $<0.001$ & $<0.002$ & $<0.002$ & 0.002 & $<0.002$ \\
\hline $\mathbf{S b}$ & $\mathbf{W}$ & $\mathbf{B}$ & $\mathbf{C a}$ & $\mathbf{Z r}$ & $\mathbf{N}_{\mathbf{2}}$ & \\
\hline$<0.002$ & $<0.003$ & 0.0002 & $<0.0002$ & $<0.001$ & 0.0024 & \\
\hline
\end{tabular}

Table 3 Chemical composition of material - E [wt.\%]

\begin{tabular}{|c|c|c|c|c|c|c|}
\hline $\mathbf{C}$ & $\mathbf{M n}$ & $\mathbf{S i}$ & $\mathbf{P}$ & $\mathbf{S}$ & $\mathbf{A l}$ & $\mathbf{C u}$ \\
\hline 0.0027 & 0.209 & 1.630 & 0.046 & 0.0010 & 0.138 & 0.013 \\
\hline $\mathbf{N i}$ & $\mathbf{C r}$ & $\mathbf{A s}$ & $\mathbf{N b}$ & $\mathbf{M o}$ & $\mathbf{C o}$ & $\mathbf{S n}$ \\
\hline 0.018 & 0.030 & $<0.001$ & $<0.002$ & $<0.002$ & $<0.002$ & $<0.002$ \\
\hline $\mathbf{S b}$ & $\mathbf{W}$ & $\mathbf{B}$ & $\mathbf{C a}$ & $\mathbf{Z r}$ & $\mathbf{N}_{\mathbf{2}}$ & \\
\hline$<0.002$ & $<0.003$ & $<0.0002$ & 0.0002 & $<0.001$ & 0.0056 & \\
\hline
\end{tabular}

The mechanical properties were determined on standard specimens by a uniaxial tensile static test according to standard STN EN ISO 6982-1. From each type of tested sheet, five samples were taken for the uniaxial tensile test. The measured mechanical properties of the tested sheets are shown in Table 4 .

Table 4 Mechanical properties of the experimental electrical steels

\begin{tabular}{|c|c|c|c|c|}
\hline Direction & Material & $\mathbf{R p}_{\mathbf{0}, \mathbf{2}}[\mathbf{M P a}]$ & $\mathbf{R}_{\mathbf{m}}[\mathbf{M P a}]$ & $\mathbf{A}_{\mathbf{8 0}}[\mathbf{\%}]$ \\
\hline $0^{\circ}$ & $\mathrm{B}$ & 413 & 477 & 16.9 \\
\hline $0^{\circ}$ & $\mathrm{C}$ & 359 & 395 & 24.1 \\
\hline $0^{\circ}$ & $\mathrm{E}$ & 317 & 440 & 34.8 \\
\hline Direction & Material & $\mathbf{R p}_{\mathbf{0}, \mathbf{2}}[\mathbf{M P a}]$ & $\mathbf{R}_{\mathrm{m}}[\mathbf{M P a}]$ & $\mathbf{A}_{\mathbf{8 0}}[\%]$ \\
\hline $90^{\circ}$ & $\mathrm{B}$ & 403 & 480 & 17.5 \\
\hline $90^{\circ}$ & $\mathrm{C}$ & 358 & 398 & 25.9 \\
\hline $90^{\circ}$ & $\mathrm{E}$ & 315 & 442 & 34.4 \\
\hline
\end{tabular}

Material B achieved an average ductility value A80 in the range of $16.9-17.5 \%$. The ductility of material $\mathrm{C}$ ranged from 24.1 to $25.9 \%$ and the ductility of material $\mathrm{E}$ was $34.4-34.8 \%$. For all materials examined, the ductility values measured in the direction perpendicular to the rolling direction and the ductility 
values measured in the rolling direction were approximately the same. The materials showed no anisotropy of mechanical properties [18].

Sheets with different grain sizes were used for comparison. The microstructure of the sheets used in the experiment is shown in Fig. 3-5. The steel sheets B had a fine-grained structure (Fig. 3), while the sheets $\mathrm{E}$ had a structure with significantly larger grains (Fig. 5).

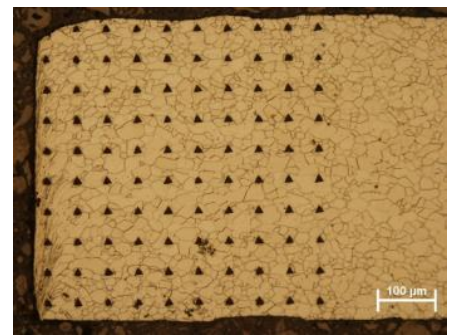

Fig. 3 Microstructure of material $B$

Fig. 4 Microstructure of material C
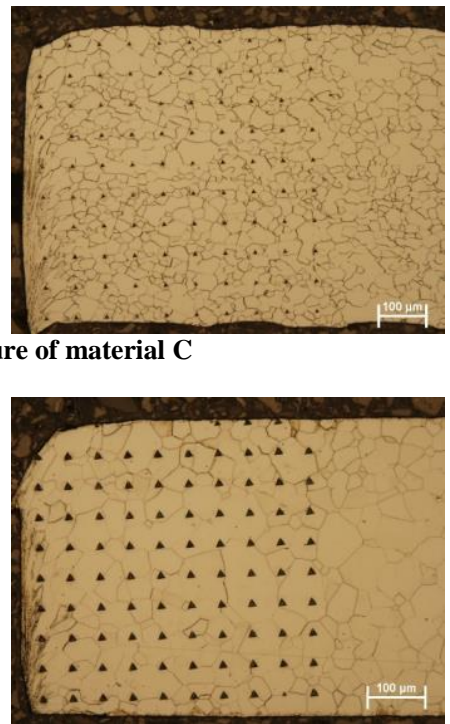

Fig. 5 Microstructure of material $E$

\section{Experimental setup, equipment, results and analysis}

Four shear gap values were chosen to investigate the dependence of the sheared surface quality on the shear gap. The chosen shear gap sizes were based on our previous research as $1 \%, 3 \%, 5 \%$ and $7 \%$ of the thickness of the sheared materials. The nominal thickness of all experimental materials was $0.5 \mathrm{~mm}$.

The experiments were conducted by blanking in a progressive shearing tool with a spring-loaded guide plate and a guide stand (Fig. 6a). The tool was used in a hydraulic press with a nominal force of $400 \mathrm{kN}$.

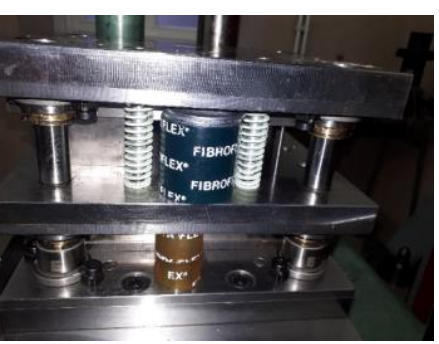

a)

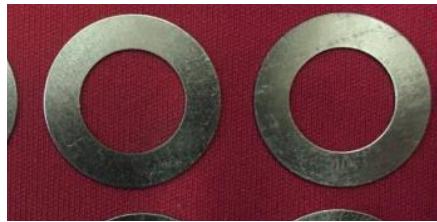

b)
Fig.6 a) Blanking tool, b) Specimen

Table 5 shows the real values of the punch diameters when 1,3, 5 and $7 \%$ shear gap was used. The dimensions of the punches were measured using a digital micrometer and Zeiss Calypso coordinate measuring machine (CMM). The diameters of the dies were constant: ø $25.013 \mathrm{~mm}$ and $\varnothing 15.049 \mathrm{~mm}$.

Table 5 Shear gap values and punch dimensions of the shearing tool

\begin{tabular}{|c|c|c|}
\hline $\begin{array}{c}\text { Shear gap } \\
{[\%]}\end{array}$ & $\begin{array}{c}\text { Diameter of outer punch } \\
{[\mathbf{m m}]}\end{array}$ & $\begin{array}{c}\text { Diameter of inner punch } \\
{[\mathbf{m m}]}\end{array}$ \\
\hline $\mathbf{1 \%}$ & 25.003 & 15.039 \\
\hline $\mathbf{3 \%}$ & 24.983 & 15.019 \\
\hline $\mathbf{5 \%}$ & 24.963 & 14.989 \\
\hline $\mathbf{7 \%}$ & 24.943 & 14.969 \\
\hline
\end{tabular}

The shape of the sheared surface on the outer perimeter of the blanks was investigated in the cutouts of an annular shape (Fig. 6b). An analysis of the outer surface of the blanks was performed with a Keyence microscope. The ratio of the plastic shear area to the gross area of the section zone was evaluated. The samples were observed around the sheared edge perimeter and evaluated in the rolling direction. Based on the observations, it can be stated that the shear area around the sheared edge perimeter was approximately the same for all blanks of a particular shear gap. The smallest deviations in the ratio of the plastic shear area to the gross section area were measured at a $1 \%$ shear gap. Significantly larger variations in the quality of the sheared surface around the perimeter of the blank were observed at a shear gap of 5\% and 7\%. Fig. 7-9 show the sheared surfaces of the investigated materials at different shear gaps [19], [20].

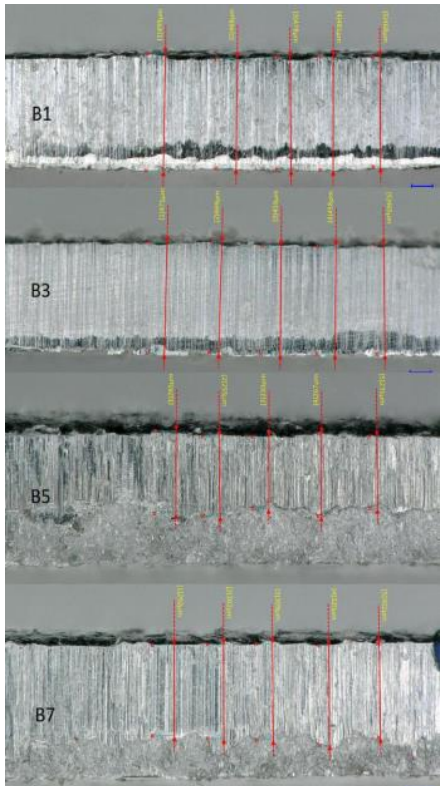

Fig. 7 Examined sheared surfaces of material B at different shear gap values

It can be concluded from the analysis of the impact the shear gap on the quality of the shear area of the examined material B that when a $1 \%$ and a $3 \%$ shear gap is used, then the entire shear area is formed by plastic shearing (plastic deformation). At these shear gaps, the material was not exposed to shear stress and there were no visible signs of shear stress around the perimeter of the cut material. At a 5\% shear gap, the smallest area of the plastic shear was measured, which was about $50 \%$ of the gross area of the section. Paradoxically, with a shear gap of $7 \%$, the plastic shear area of this material increased to about $65 \%$. This was probably due to a deviation in the punch cylindricality at the measured location. 


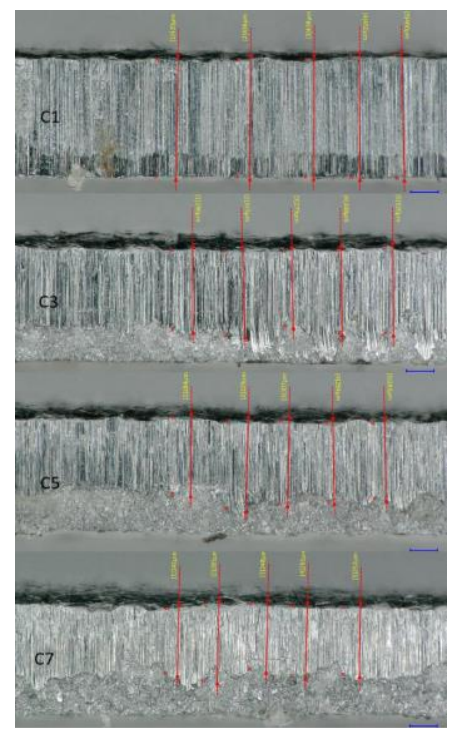

Fig. 8 Examined sheared surfaces of material $\mathrm{C}$ at different shear gap values

From the analysis of the impact of the shear gap on the quality of the shear area of the examined material $\mathrm{C}$, it can be concluded that at a $1 \%$ shear gap, the entire shear area is formed by plastic shearing (plastic deformation). There was no fracture zone at this shear gap at all. At a $3 \%$ shear gap, the plastic shear value was measured to be $100-80 \%$ of the gross area of the section. At this shear gap, uneven values of the size of the plastic shear occurred around the perimeter of the blank. At a 5\% shear gap, the plastic shear area was more uniform over the entire perimeter and represented $65-70 \%$ of the gross area of the section.

At the 7\% shear gap, the plastic shear area of the material was less uniform around the perimeter and represented $60-65 \%$ of the gross area of the section.

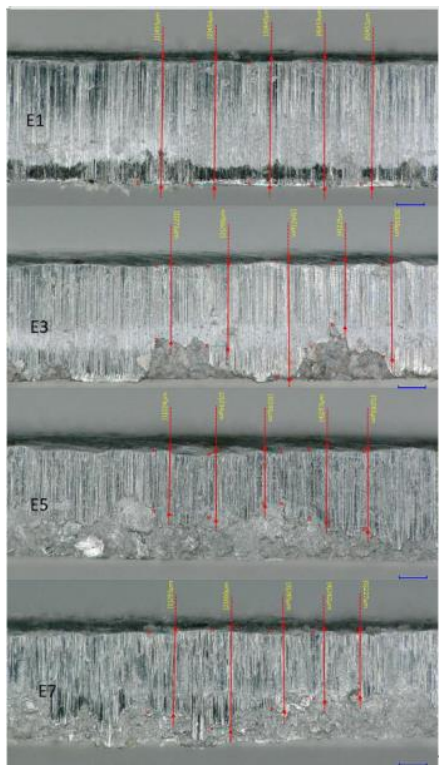

Fig. 9 Examined sheared surfaces of material $\mathrm{E}$ at different shear gap values

It can be concluded from the analysis of the impact of the shear gap on the quality of the sheared surface of the investigated material $\mathrm{E}$ that at a $1 \%$ shear gap, the entire shear area is formed by plastic shearing (plastic deformation). There was no shear stress at this shear gap at all. At a 3\% shear gap, the plastic shear area was measured to be about $90-50 \%$ of the gross area of the section. At this shear gap, an uneven plastic shear area occurred around the perimeter of the blank. During die-cutting, large grains were torn off the perimeter of the material.
The same phenomenon was also observed at 5 and $7 \%$. The plastic shear area was uneven around the perimeter of the blank and ranged from 100 to $50 \%$. Fig. 10 and 11 enable us to compare the shear area of the investigated materials at $1 \%$ and 5\% shear gap. As stated above, at a 1\% shear gap, all experimental materials were exposed to plastic shear around the perimeter of the blank. At this shear gap, the quality of the sheared surface is not influenced by the chemical composition of the sheet nor by the mechanical and plastic properties of the investigated electrical steel sheets.

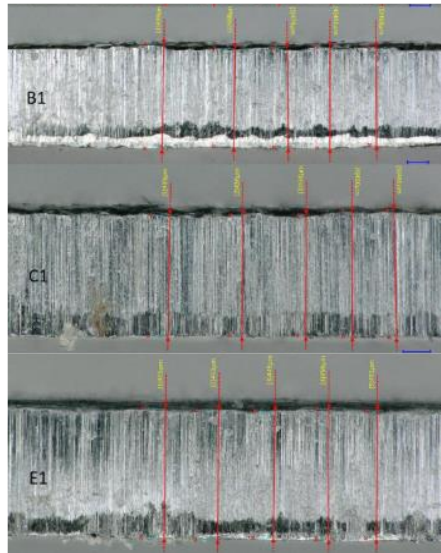

Fig. 10 Sheared surfaces of investigated materila at $1 \%$ shear gap

After analyzing the sheared surfaces of the specimens at the 5\% shear gap, it can be stated that the plastic shear area was in the range of $100-50 \%$ of the gross area of the section. The lowest plastic shear value was measured for material $\mathrm{B}$, whose ductility values were the lowest. The shear area of this material was uniform around the perimeter. For material $\mathrm{C}$, the plastic shear value at a $5 \%$ shear gap ranged from 70 to $65 \%$ and it was less uniform. Material $\mathrm{E}$ had the highest ductility of all the examined materials, the plastic shear area at this shear gap ranged from 100 to $50 \%$. Such a large dispersion of the plastic shear values is caused by tearing off large grains of material during die cutting [21], [22].

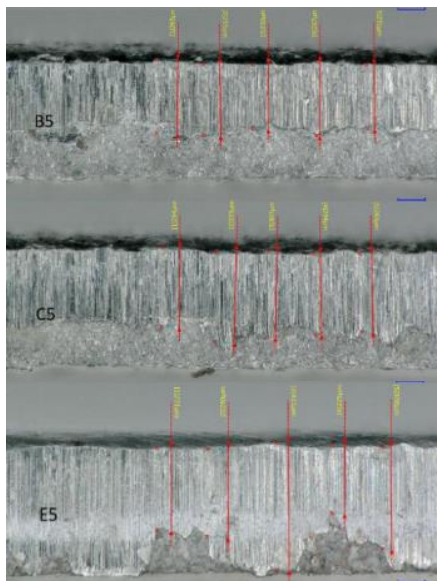

Fig. 11 Sheared surfaces of investigated materials at $5 \%$ shear gap

\section{DISCUSSION}

In the experimental research into the impact of the shear gap on the quality of the sheared surface, materials with different chemical composition, mainly differing in silicon content were selected. The examined materials had different mechanical and plastic properties. The ductility of the examined materials ranged from 16 to $35 \%$. The materials also differed in the manufacturing method and grain size. All investigated materials exhibited minimal anisotropy of the plastic properties (they were almost isotropic), which is a very important factor in terms of punching circular blanks. From the obtained results it can be concluded that at a $1 \%$ shear gap, the chemical composition, plastic properties or material structure 
do not affect the quality of the sheared surface as indicated by the size of the plastic shear area. The plastic shear area of all materials examined was $100 \%$ of the gross area of the section.

At the shear gap of 3\%, the impact of the material structure began to be obvious. The plastic shear areas reached $100 \%$ only for material B, for the other examined materials, they ranged from 80 to $50 \%$ of the gross area of the section. Material $\mathrm{E}$, having the highest ductility, exhibited the lowest and least uniform values of the plastic shear area. These plastic shear areas were somewhat distorted in this material because large grains of material were torn off during die cutting.

At 5 and $7 \%$ shear gap, all materials showed a decrease in the plastic shear area to $70-50 \%$ of the gross area of the section. With these shear gaps, the inhomogeneity of the plastic shear area around the perimeter of the blank was lower for all examined materials. Even at these shear gaps, the greatest inhomogeneity of the plastic shear areas was observed in the material with the highest ductility (material E).

\section{CONCLUSION}

Based on the experimental results of the impact of the shear gap on the quality of the sheared surface when die-cutting electrical sheets of different grades, the following conclusions can be drawn:

- when shearing electrical steel sheets in a tool with a shear gap of $1 \%$ of the material thickness, neither the chemical composition nor the mechanical and plastic properties affect the quality of the sheared surface, which is characterized by the size of the plastic shear area,

- blanking materials in a tool with a shear gap of $3 \%$ of the material thickness results in a decrease in the size of the plastic shear area, especially for materials with a higher ductility value,

- when die-cutting sheets in a tool with a shear gap of 5 and $7 \%$ of the material thickness, the plastic shear areas decreased for all materials examined. The greatest inhomogeneity of the plastic shear area was measured for the sheets with the highest ductility. In these sheets, the inhomogeneity was mainly caused by the large grains of material being torn off during die cutting.

Based on the performed experiments, it is recommended to use shear gaps in the range of $1-2 \%$ of the material thickness in the blanking tools for trouble-free cutting of circular cut-outs made of electrical steel sheets (rotors and stators of electric rotating machines).

Acknowledgments: Authors are grateful to APVV for support of experimental work under grant APVV-14-0834 and APVV-17-0381.

\section{REFERENCES}

1. [11.4.2006] http://www.worldsteel.org/steel-by-topic/statistics/steel-statisticalyearbook.html, Steel Statistical Yearbooks 2010 to 2019

2. E. Spišák, J. Slota, J. Majerníková: Chemické listy, 105, 2011, p. 485-487

3. R. Bidulsky, J. Bidulska, P. Petrousek, A. Fedorikova, E. Dudrova, M.A. Grande: Acta Physica Polonica A, 131(5), 2017, 1367-1370.

https://doi.org/10.12693/APhysPolA.131.1367.

4. R. Bidulsky, J. Bidulska, R. De Oro, E. Hryha, M. Maccarini, I. Forno, M.A. Grande: Acta Physica Polonica A, 128(4), 2015, 647-650.

https://doi.org/10.12693/APhysPolA.128.647.

5. R. Bidulsky, M.A. Grande, L. Ferraris, P. Ferraris, J. Bidulska: Acta Physica Polonica A, 118(5), 2010, 802-803.

https://doi.org/10.12693/APhysPolA.118.802.

6. J. T. Park, J. K. Kim: Recrystallization, Grain growth and texture evolution in nonoriented electrical steel, Mater. Sci. Forum, 10(1), 2007, 657-664. https://doi.org/10.4028/www.scientific.net/MSF.558-559.657.

7. P. M. Carlberg: The cutting of electrical steel sheets, In.: Translation of presentation at the Kernkontoret Punching Conference, Stockholm, November 1971.

8. K. H. Schmidt: Journal of Magnetism and Magnetic Materials, 2, 1975, 136. https://doi.org/10.1016/0304-8853(75)90116-X.

9. T. Nakata, M. Nakano, K. Kawahara: IEEE Transactions on Magnetics, 7, 1992, 453-457. https://doi.org/10.1109/TJMJ.1992.4565422.

10. F. Ossart, E. Hug, O. Hubert, C. Buvat, R. Billardon: IEEE Transactions on Magnetics, Vol. 36, 2000, 3137-3140. https://doi.org/10.1109/20.908712.
11. Kedous-Lebouc, B. Cornut, J. C. Perrier, Ph. Manfé, Th. Chevalier: Journal of Magnetism and Magnetic Materials, 254-255, 2003, 124-126. https://doi.org/10.1016/S0304-8853(02)00803-X.

12. V. Manescu, G. Paltanea, H. Gavrila, I. Peter: The Influence of Punching and Laser Cutting Technologies on the Magnetic Properties of Non-oriented Silicon Iron Steels, In.: International Symposium on Fundamentals of Electrical Engineering, University Politehnica of Buchurest, Nov. 2014

13. N. Takahashi, H. Morimoto, Y. Yunoki, D. Miyagi: Journal of Magnetism and Magnetic Materials, 320, 2008, e925-e928. https://doi.org/10.1016/j.jmmm.2008.04.170.

14. Yujing Liu, S. K. Kashif, A. M. Sohail: Engineering considerations on additional iron losses due to rotational fields and sheet cutting, In.: International Conference on Electrical Machines, 2008.

15. J. Talbot: Recovery and Recrystallization of Metals, Interscience, New York, 1963, p. 269.

16. H. Hu: Recovery and Recrystallization of Metals, Interscience, New York, 1963, p. 311.

17. F. J. G. Landgraf, M. Emura: Journal of Magnetism and Magnetic Materials, 242, 2002, 152-156. https://doi.org/10.1016/S0304-8853(01)01184-2.

18. J. Majerníková, E. Spišák: Applied Mechanics and Materials, 474, 2014, 279284. https://doi.org/10.4028/www.scientific.net/AMM.474.279.

19. J. Majerníková, E. Spišák: Advances in Science and Technology Research Journal. 11(4), 2017, 141-146. https://doi.org/10.12913/22998624/78168.

20. E. Spišák, L. Kaščák, J. Majerníková, M. Džupon: Strength of Materials, 49(4), 2017, 605-611. https://doi.org/10.1007/s11223-017-9904-2.

21. E. Spišák, J. Majerníková, L. Kaščák: Advances in Science and Technology Research Journal. 10(32), 2016, 248-253. https://doi.org/10.12913/22998624/65759.

22. Záverečná správa projektu APVV-14-0834, Technical University of Košice, 2018 (in Slovak). 